\title{
ОПТИМІЗАЦІЯ АНТИТРОМБОЦИТАРНОЇ ТЕРАПІЇ У ХВОРИХ НА СТАБІЛЬНУ ІШЕМІЧНУ ХВОРОБУ СЕРЦЯ НА ТЛІ НЕАЛКОГОЛЬНОЇ ЖИРОВОЇ ХВОРОБИ ПЕЧІНКИ У СТАДІї СТЕАТОГЕПАТИТУ
}

\author{
ДВНЗ «Івано-Франківський національний медичний університет»
}

РЕЗЮМЕ. Вступ. Показник серцево-судинної смертності за умов наявності неалкогольного стеатогепатиту (НАСГ) значно переважає показник смертності від захворювань печінки. Встановлено, що неалкогольна жирова хвороба печінки (НАЖХП) тісно асоціюється з протромботичним станом, що пояснюється безпосередньою участю печінки у гемостазі

Мета - підвищення ефективності та безпечності антитромбоцитарної терапії (АТT) у комплексному лікуванні хворих із постінфарктним кардіосклерозом на тлі НАЖХП у стадії стеатогепатиту.

Матеріал і методи. Обстежено 211 хворого на стабільну ішемічну хворобу серця (IXC) ФК II-III, серед яких виділяли 160 осіб без НАЖХП (І група); 51 особу з НАЖХП у стадії стеатогепатиту (II група). Усім хворим проводили загальноклінічне обстеження, електрокардіографію, ехокардіографію, коронарографію, ультразвукове дослідження і оцінку функціонального стану печінки та тромбоцитарної ланки гемостазу. Хворі отримували стандартну терапію відповідно до діючих клінічних протоколів. Оцінку ефективності лікування проводили через 3 та 6 місяців терапії.

Результати. Встановлено, що ефективність АТТ за показниками агрегаційної активності тромбоцитів залежить від наявності НАЖХП, тривалості лікування, тяжкості ураження печінки на тлі НАСГ і, відповідно, обраної схеми диференційованої АТТ. Визначено достатню ефективність АТТ вже через 3 місяці її застосування у хворих на стабільну IXC без НАЖХП. Натомість Хворі на стабільну IXC, поєднану з НАЖХП у стадії НАСГ, потребують більш тривалого проведення корекції тромбоцитарного гемостазу з обов'язковим застосуванням диференційованого підходу до АТТ відповідно до тяжкості ураження печінки.

Висновки. Ефективність впливу на тромбоцитарну ланку гемостазу за показниками агрегаційної активності тромбоцитів у хворих на стабільну ІХС залежить від наявності НАЖХП і тяжче піддається контролю при НАСГ. У хворих на стабільну IXC, поєднану з НАЖХП у стадії стеатогепатиту, доцільним є контроль ефективності АТТ кожні 3 місяці ії̈ застосування та, за необхідності, проведення ії корекції, що передбачає розгляд можливості іï̈ посилення чи подвоєння залежно від стану печінки.

КлючОВІ СлОВА: стабільна ішемічна хвороба серця; неалкогольна жирова хвороба печінки; антитромбоцитарна терапія.

Вступ. На сьогоднішній день ішемічна хвороба серця (IXC) залишається провідною причиною серцево-судинної смертності та щорічно обумовлює зростання відсотка інвалідизації працездатного населення у світі та в Україні зокрема [1]. У свою чергу, неалкогольна жирова хвороба печінки (НАЖХП) займає одну з провідних позицій серед дифузних захворювань печінки в усьому світі, а частота ії виникнення сягає $17-33$ \% у загальній популяції хворих [2]. НАЖХП класифікується на кілька стадій, що включають стеатоз, стеатогепатит, фіброз і цироз печінки, які відображають її поступове прогресування. Більше того, встановлено, що НАЖХП прогресує в неалкогольний стеатогепатит (НАСГ) у $13-33$ \% випадків [3, 4]. Окрім того, відомо, що у хворих із НАЖХП спостерігається значно вища частота серцево-судинних захворювань, ніж у пацієнтів без НАЖХП, незалежно від наявності факторів ризику кардіоваскулярної патології $[5,6]$. Зокрема, показник серцево-судинної смертності за умов наявності НАСГ значно переважає показник смертності від захворювань печінки, складаючи при цьому $36 \%$ проти 6,8 \% [7].
Встановлено, що НАЖХП тісно асоціюєТься 3 протромботичним станом, що пояснюється безпосередньою участю печінки у гемостазі $[8,9]$. Більшість коагуляційних факторів, антикоагулянтні білки та компоненти фібринолітичної системи синтезуються печінковими паренхіматозними клітинами [10]. Тому важлива роль у лікуванні хворих із такою поєднаною патологією належить саме антитромбоцитарній терапії (АТТ). Однак особливу увагу привертає цілий ряд невирішених питань, а саме - можливість, ефективність та безпечність застосування АТT при стабільній IXC, поєднаній з НАЖХП у стадії стеатогепатиту.

Мета дослідження - підвищення ефективності та безпечності АТТ у комплексному лікуванні хворих із постінфарктним кардіосклерозом на тлі НАЖХП у стадії стеатогепатиту.

Матеріал і методи дослідження. Об'єктом дослідження був 211 хворий (середній вік $(54,2 \pm 5,3)$ років) на стабільну IXC ФК II-III, які перенесли гострий коронарний синдром більше 3 місяців тому. За даними детального клініко-діагностичного обстеження хворі були поділені за наяв- 
Огляди літератури, оригінальні дослідження, погляд на проблему

ністю НАЖХП. Зокрема, було виділено 160 осіб без НАЖХП (І група) та 51 особа з НАЖХП у стадії стеатогепатиту (II група). Контрольну групу склали 20 практично здорових осіб.

Діагноз стабільної IXC був верифікований за даними електрокардіографії, результатами коронарографії та наявністю в анамнезі перенесеного інфаркту міокарда відповідно до уніфікованого клінічного протоколу «Стабільна ішемічна хвороба серця» (Наказ МОЗ України № 152 від 02.03.2016 року) [11]. Діагноз НАЖХП встановлювали відповідно до уніфікованого клінічного протоколу «Неалкогольний стеатогепатит» (Наказ МОЗ України № 826 від 06.11.2014 року) [12], Адаптованої клінічної настанови «Неалкогольна жирова хвороба печінки» [13], згідно з рекомендаціями Європейської асоціації з вивчення печінки (EASL), Європейської асоціації $з$ вивчення діабету (EASD), Європейської асоціації з вивчення ожиріння (EASO) [14].

Усім хворим проводили загальноклінічне обстеження (аналіз скарг, анамнезу хвороби, анамнезу життя, об'єктивного статусу), електрокардіографію, ехокардіографію, коронарографію, ультразвуковедослідження печінки, оцінку функціонального стану печінки та тромбоцитарної ланки гемостазу.

Тромбоцитарний гемостаз оцінювали за показниками агрегаційної активності тромбоцитів (ступінь агрегації, швидкість агрегації, час агрегації, кількість тромбоцитів, фактор Віллебрандта) за допомогою агрегометра AP 2110 «Солар» (Білорусія) 3 використанням аденозиндифосфату 2,5 мкмоль/л за загальновизнаною методикою [15].

Всі залучені до дослідження хворі отримували стандартну терапію, що включала бета-адреноблокатори, нітрати пролонгованої дії, антагоністи кальцію, інгібітори АПФ чи сартани (за необхідності), ацетилсаліцилову кислоту у дозі 75 мг на добу всередину й індивідуально підібрану гіполіпідемічну та гепатопротекторну терапію залежно від тяжкості ураження печінки. Оцінку ефективності та корекцію АТТ проводили через 3 місяці після застосованого лікування. Зокрема, через 3 місяці терапії в II групі виділяли хворих із достатньо ефективною АТТ (підгрупа A) (n=18) і хворих із недостатньо ефективною АТТ (підгрупа Б) ( $n=33)$. Відповідно, за умов достатньої ефективності АТT пацієнти IIA групи продовжували отримувати ацетилсаліцилову кислоту у дозі 75 мг на добу всередину. При недостатньо ефективній АТТ у хворих ІІБ групи проводили ії корекцію: пацієнтам із задовільним станом печінки за результатами діагностичних тестів призначали посилену ATT, що включала ацетилсаліцилову кислоту у дозі 75 мг 2 рази на добу всередину ( $n=9)$; хворим із незадовільним станом печінки за результатами діагностичних тестів призначали подвійну АТT, що включала ацетилсаліцилову кислоту у дозі 75 мг на добу всередину та клопідогрель у дозі 75 мг на добу всередину ( $n=24)$. Через 6 місяців лікування проводили повторну оцінку ефективності, безпечності та, за необхідності, корекцію антитромбоцитарної терапії.

Статистичну обробку отриманих результатів проводили за допомогою програмного забезпечення - табличного процесора «Microsoft Excel» та пакета прикладних програм «Statistica» v. 10.0 StatSoft, USA. Оцінку вірогідності розходження середніх величин проводили за допомогою парного t-критерію Стьюдента. Середні величини подані у вигляді $(\mathrm{M} \pm \mathrm{m})$, де $\mathrm{M}$ - середн $є$ значення показника, $\mathrm{m}$ - стандартна похибка середнього. Результати вважали статистично достовірними при значенні $\mathrm{p}<0,05$.

Результати й обговорення. Встановлено, що ефективність АТТ за показниками агрегаційної активності тромбоцитів залежить від наявності НАЖХП, тривалості лікування, тяжкості ураження печінки на тлі НАСГ і, відповідно, обраної схеми диференційованої АТТ (табл. 1). Зокрема, час агрегації у хворих I групи впродовж всього періоду лікування поступово наростав, досягши величини контролю вже через 3 місяці лікування. При цьому, якщо через 3 місяці терапії цей показник був більшим на $18,4 \%$, порівняно з базальним рівнем, то через 6 місяців його величина залишалась стабільною, будучи вищою на 15,9\%, порівняно з вихідним значенням $(p<0,05)$. У свою чергу, у хворих IIA групи час агрегації через 3 місяці терапії збільшився на 17,6 \%, порівняно з базальним рівнем $(p<0,05)$. Натомість, в ІІБ групі спостерігали лише тенденцію до наростання цього показника ( $>>0,05)$.

При цьому через 6 місяців лікування у хворих IIA групи час агрегації зріс на 41,2 \%, порівняно 3 його початковим значенням, і на 20,1 \% - порівняно з показником через 3 місяці терапії $(p<0,05)$. Більше того, у хворих ІІБ групи зміни цього показника залежали від застосованої схеми АТТ і були більш суттєвими при подвійній АТТ. Зокрема, через 6 місяців застосування посиленої АТТ час агрегації збільшився на 23,7 \%, порівняно з базальним рівнем, та на 16,4 \% - порівняно з показником через 3 місяці лікування $(p<0,05)$. У свою чергу, при подвійній АТТ цей показник збільшився на $31,0 \%$, порівняно з його вихідним значенням, що було вище на 23,3 \% відносно показника через 3 місяці лікування $(p<0,05)$.

Подібні закономірності змін спостерігали за швидкістю агрегації. Зокрема, у хворих I групи цей показник через 3 місяці лікування зменшився на $16,1 \%$, порівняно з базальним рівнем $(p<0,05)$, тобто досяг величини контролю та залишився на 
Огляди літератури, оригінальні дослідження, погляд на проблему

Таблиця 1. Динаміка показників тромбоцитарної ланки гемостазу та ендотеліальної функції у хворих на



\begin{tabular}{|c|c|c|c|c|c|c|c|c|c|c|c|}
\hline \multirow{4}{*}{\multicolumn{2}{|c|}{$\begin{array}{c}\text { Показник, } \\
\text { одиниці } \\
\text { виміру }\end{array}$}} & \multirow{4}{*}{$\begin{array}{c}\text { Конт- } \\
\text { рольна } \\
\text { група } \\
(n=20)\end{array}$} & \multicolumn{3}{|c|}{ I група (n=160) } & \multicolumn{6}{|c|}{ II група $(n=51)$} \\
\hline & & & \multirow[b]{3}{*}{$\begin{array}{c}\text { базаль- } \\
\text { ний } \\
\text { рівень }\end{array}$} & \multirow[b]{3}{*}{$\begin{array}{c}\text { через } \\
3 \text { місяці }\end{array}$} & \multirow[b]{3}{*}{$\begin{array}{c}\text { через } \\
6 \text { міся- } \\
\text { ців }\end{array}$} & \multirow[b]{3}{*}{$\begin{array}{c}\text { базаль- } \\
\text { ний } \\
\text { рівень }\end{array}$} & \multicolumn{2}{|c|}{ через 3 місяці } & \multicolumn{3}{|c|}{ через 6 місяців } \\
\hline & & & & & & & \multirow[b]{2}{*}{$\begin{array}{c}\text { IIA група } \\
(n=18)\end{array}$} & \multirow[b]{2}{*}{$\begin{array}{c}\text { ІІБ } \\
\text { група } \\
(n=33)\end{array}$} & \multirow[b]{2}{*}{$\begin{array}{c}\text { IIA група } \\
(n=18)\end{array}$} & \multicolumn{2}{|c|}{ ІІБ група } \\
\hline & & & & & & & & & & $\begin{array}{c}\text { посиле- } \\
\text { на } \\
\text { АТТ } \\
(n=9)\end{array}$ & $\begin{array}{c}\text { подвій- } \\
\text { на } \\
\text { АTТ } \\
(n=24)\end{array}$ \\
\hline \multirow{18}{*}{ 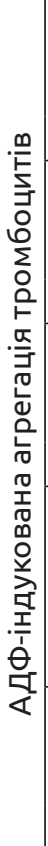 } & Час агре- & 15,70 & 13,49 & 15,97 & 15,63 & 8,73 & 10,27 & 9,28 & 12,33 & 10,80 & 11,44 \\
\hline & гації, с & $\pm 1,84$ & $\pm 1,83$ * & $\pm 1,32 * \S$ & $\pm 1,05 * \S$ & $\pm 0,48 * \&$ & $\pm 0,92$ & $\pm 0,75$ & $\pm 1,34$ & $\pm 0,86$ & $\pm 1,17$ \\
\hline & & & & 2 & ? & & * §\& & * \& & * §ળ\& & * §ળ\& & * §ી\& \\
\hline & \begin{tabular}{|r|}
$\Delta$ \\
|lpunkictb
\end{tabular} & & & $\begin{array}{l}+2,48 \\
1361\end{array}$ & $\begin{array}{l}+2,14 \\
1388\end{array}$ & & $\begin{array}{l}+1,54 \\
1082\end{array}$ & $\begin{array}{l}+0,55 \\
20,83\end{array}$ & $+3,60$ & $\frac{07}{23}$ & $\begin{array}{l}+2,71 \\
16,22\end{array}$ \\
\hline & $\begin{array}{l}\text { ШВидКІсть } \\
\text { агрегації, }\end{array}$ & $\begin{array}{r}14,13 \\
\pm 0,30\end{array}$ & $\begin{array}{l}16,23 \\
\pm 0,42 \text { * }\end{array}$ & $\begin{array}{c}13,61 \\
\pm 0,28 * \S\end{array}$ & $\begin{array}{c}13,88 \\
\pm 0,32 * \S\end{array}$ & $\begin{array}{c}22,35 \\
\pm 1,32 *\end{array}$ & $\begin{array}{l}19,82 \\
\pm 0,87\end{array}$ & $\begin{array}{l}20,83 \\
\pm 1,08\end{array}$ & $\begin{array}{l}15,94 \\
\pm 0,56\end{array}$ & $\begin{array}{l}17,33 \\
\pm 0,52\end{array}$ & $\begin{array}{l}16,23 \\
\pm 0,67\end{array}$ \\
\hline & $\% / c$ & & & & & $\&$ & * §\& & * \& & * §ণा\& & * §ণ\& & * §ળ\& \\
\hline & $\Delta$ & & & $-2,62$ & $-2,35$ & & $-2,53$ & $-1,52$ & $-6,41$ & $-5,02$ & $-6,12$ \\
\hline & Ступінь & 21,08 & 24,26 & 19,63 & 20,57 & 33,14 & 29,03 & 30,65 & 22,73 & 25,07 & 23,45 \\
\hline & агрегації, & $\pm 0,68$ & $\pm 0,34$ * & $\pm 0,26 * \S$ & $\pm 0,43 * \S$ & $\pm 1,64$ * & $\pm 1,12$ & $\pm 1,26$ & $\pm 0,82$ & $\pm 0,45$ & $\pm 0,92$ \\
\hline & & & & & & $\&$ & * §\& & * \& & * §ा\& & *§ণ\& & * §ा\& \\
\hline & $\Delta$ & & & $-4,63$ & $-3,69$ & & $-4,11$ & $-2,49$ & $-10,41$ & $-8,07$ & $-9,69$ \\
\hline & Кількість & 268,25 & 305,81 & 249,14 & 254,28 & 421,41 & 363,26 & 386,01 & 277,89 & 313,82 & 292,59 \\
\hline & тромбо- & $\pm 10,56$ & $\pm 12,61$ * & $\pm 8,12 * \S$ & $\pm 7,62 * \S$ & $\pm 12,35$ & $\pm 11,64$ * & $\pm 12,08$ * & $\pm 10,31$ & $\pm 11,34$ & $\pm 10,86$ \\
\hline & $\begin{array}{l}\text { цитів, } \\
\text { тис. /Мкл }\end{array}$ & & & & & $* 8$ & $\S \&$ & $\S \&$ & * §П\& & * §ળ\& & * §П\& \\
\hline & $\Delta$ & & & $-56,67$ & $-51,53$ & & $-58,15$ & $-35,40$ & $-143,52$ & $-107,59$ & $-128,82$ \\
\hline & Фактор & 189,26 & 218,89 & 183,89 & 192,36 & 296,16 & 258,84 & 274,83 & 201,86 & 226,45 & 212,44 \\
\hline & $\begin{array}{l}\text { Вілле- } \\
\text { бранда \% }\end{array}$ & $\pm 7,19$ & $\pm 11,28$ * & $\pm 7,23 * \S$ & $\pm 6,84 * \S$ & $\begin{array}{c} \pm 11,27 \text { * } \\
\&\end{array}$ & $\begin{array}{c} \pm 10,22 \text { * } \\
\text { \&\& }\end{array}$ & $\begin{array}{c} \pm 10,34 \text { * } \\
\text { \&\& }\end{array}$ & $\begin{array}{l} \pm 8,17 \\
* 89 \&\end{array}$ & $\begin{array}{l} \pm 10,76 \\
\text { * ธา\& }\end{array}$ & $\begin{array}{c} \pm 10,64 \\
\text { * 8า \& }\end{array}$ \\
\hline & $\Delta$ & & & $-35,0$ & $-26,53$ & & $-37,32$ & $-21,33$ & $-94,30$ & $-69,71$ & $-83,72$ \\
\hline
\end{tabular}

Примітка. * - достовірність різниці порівняно з контрольною групою $(p<0,05)$; §-достовірність різниці після лікування порівняно з базальним рівнем у групі (p<0,05); П - достовірність різниці через 6 місяців лікування порівняно з показником через 3 місяці лікування у групі ( $<<0,05) ; \&$ - достовірність різниці порівняно з відповідним показником у хворих I групи $(p<0,05) ; \Delta-$ різниця зміни показника у групі після лікування відносно базального рівня.

тому ж рівні через 6 місяців терапії. У свою чергу, у хворих ІІА групи швидкість агрегації через 3 місяці лікування зменшилась на $11,3 \%$, порівняно 3 початковим значенням ( $p<0,05)$. При цьому через 6 місяців терапії динаміка зменшення цього показника була більш суттєвою та складала 28,7 \%, порівняно з базальним рівнем, і 19,6\% - порівняно з показником через 3 місяці лікування відповідно $(p<0,05)$. Натомість у хворих ІІБ групи швидкість агрегації через 3 місяці терапії зменшилась лише на 6,8 \%, порівняно з їі вихідним значенням $(p>0,05)$. Через 6 місяців посиленої АТТ цей показник зменшився на $22,5 \%$, порівняно з базальним рівнем, та був на $16,8 \%$ меншим, порівняно з показником через 3 місяці лікування $(p<0,05)$. Більше того, під впливом 6-місячної подвійної АТТ швидкість агрегації зменшилась на 27,4 \%, порівняно $з$ початковим рівнем, та на $22,1 \%$ - порівняно з показником через 3 місяці лікування $(p<0,05)$.

Ступінь агрегації у хворих I групи досяг величини контролю вже через 3 місяці терапії, знизившись при цьому на 19,1 \%, порівняно з базальним рівнем $(p<0,05)$. У хворих IIA групи динаміка зменшення цього показника через 3 місяці лікування була менш суттєвою та складала 12,4 \%, порівняно з вихідним значенням $(p<0,05)$. Однак через 6 місяців лікування цей показник знизився на $31,4 \%$, порівняно з початковим рівнем, і на 21,7 \% - порівняно з показником через 3 місяці терапії $(p<0,05)$. У свою чергу, у хворих ІІБ групи через 3 місяці лікування цей показник зменшився лише на $7,5 \%$, порівняно з його вихідним значенням $(p>0,05)$. Однак через 6 місяців посиленої АТТ ступінь агрегації знизився на 24,4 \%, порівняно з базальним рівнем, і на 18,2 \% - порівняно зі значенням через 3 місяці лікування $(p<0,05)$. Натомість через 6 місяців подвійної АТТ цей показник зменшився на 29,2 \%, порівняно з вихідним рівнем, що було менше на 23,5 \% порівняно з відповідним показником через 3 місяці терапії $(p<0,05)$.

Різниця зміни кількості тромбоцитів відносно базального рівня у хворих I групи через 3 місяці лікування склала $-56,67$, що обумовило досягнення величини цього показника рівня контролю 
Огляди літератури, оригінальні дослідження, погляд на проблему

$(p<0,05)$. Натомість, у хворих IIA групи різниця зміни цього показника через 6 місяців лікування склала $-143,52$ проти -58,15 - через 3 місяці терапії $(p<0,05)$ відповідно. У свою чергу, у хворих ІІБ групи, в котрих застосовували посилену АТТ, даний показник через 6 місяців лікування становив -107,59, порівняно $3-35,40$ - через 3 місяці терапії $(p<0,05)$ відповідно. Під впливом подвійної АТТ у хворих ІІБ групи різниця зміни кількості тромбоцитів відносно початкового рівня складала $-128,82$, що було на 19,7 \% більше, порівняно з хворими ІІБ групи, які отримували посилену АТТ $(p<0,05)$.

Фактор Віллебранда у хворих I групи вже через 3 місяці лікування досяг величини в контролі, зменшившись на 16,0 \%, порівняно з базальним рівнем $(p<0,05)$. У хворих IIA групи цей показник через 3 місяці лікування знизився на 12,6\%, порівняно з його початковим значенням $(p<0,05)$. Натомість через 6 місяців терапії у хворих IIA групи фактор Віллебранда досяг найсуттєвішого зниження - був меншим на 31,8 \%, порівняно з базальним рівнем, та на 22,0 \% - порівняно з показником через 3 місяці лікування $(p<0,05)$. У свою чергу, у хворих ІІБ групи через 3 місяці терапії цей показник мав лише тенденцію до зниження $(p>0,05)$. Проте через 6 місяців лікування фактор Віллебранда під впливом посиленої АТТ знизився на $23,5 \%$, порівняно з вихідним значенням, та на 12,5\% - порівняно з відповідним показником через 3 місяці лікування $(p<0,05)$. Більше того, під впливом подвійної

\section{ЛІТЕРАТУРА}

1. Коваленко В. М. Проблеми здоров'я і медичної допомоги та модель покращення в сучасних умовах / В. М. Коваленко, В. М. Корнацький, Д. М. Мороз. - К., 2016. - 261 c.

2. World Gastroenterology Organization. Nonalcoholic Fatty Liver Disease and Nonalcoholic Steatohepatitis: World Gastroenterology Organisation Global Guidelines // World Gastroenterology Organisation. 2012 [cited 2012 Dec 1]. Available from: http://www.worldgastroenterology.org/NAFLD-NASH.html.

3. Зайцева О. Е. Неалкогольный стеатогепатит. Больше чем просто стеатоз? / О. Е. Зайцева // Тһегаріа. 2016. - № 7. - С. 111.

4. Степанов Ю. М. Стеатоз печени и стеатогепатит - неизбежность смешанного генеза / Ю. М. Степанов // Гастроентерологія. - 2014. - № 4. - С. 136-142.

5. Фадєєнко Г. Д. Коморбідна патологія, що впливає на серцево-судинний ризик у постінфарктних хворих / Г. Д. Фадєєнко, В. А. Чернишов // Український терапевтичний журнал. - 2014. - № 2. - С. 11-20.

6. World Gastroenterology Organization. Obesity: World Gastroenterology Organization Global Guideline // World Gastroenterology Organization. 2012 [cited 2012 Dec 1]. Available from: http://www.worldgastroenterology.org/obesity.html.
АТТ цей показник зменшився на 28,3 \%, порівняно з його базальним рівнем, та на 22,7 \% - порівняно з показником через 3 місяці лікування $(p<0,05)$.

Таким чином, описана динаміка змін агрегаційної активності тромбоцитів під впливом лікування встановила достатню ефективність АТТ вже через 3 місяці її застосування у хворих на стабільну IXC без НАЖХП. Натомість, хворі на стабільну IXC, поєднану з НАЖХП у стадії НАСГ, потребують більш тривалого проведення корекції тромбоцитарного гемостазу з обов'язковим застосуванням диференційованого підходу до АТТ відповідно до тяжкості ураження печінки.

Висновки. 1. Ефективність впливу на тромбоцитарну ланку гемостазу за показниками агрегаційної активності тромбоцитів у хворих на стабільну IXC залежить від наявності НАЖХП і тяжче піддається контролю при НАСГ.

2. У хворих на стабільну IXC, поєднану 3 НАЖХП у стадії стеатогепатиту, доцільним $\epsilon$ контроль ефективності АТТ кожні 3 місяці її застосування та, за необхідності, проведення її корекції, що передбачає розгляд можливості їі посилення чи подвоєння залежно від стану печінки.

Перспективи подальших досліджень. Подальші дослідження необхідно спрямувати на розробку нових диференційованих підходів до довготривалої АТТ у хворих на стабільну IXC на тлі НАЖХП у стадії стеатогепатиту, яким були проведені втручання з реваскуляризації міокарда.

7. Francque S. M. Non-alcoholic fatty liver disease and cardiovascular risk: Pathophysiological mechanisms and implications / S. M. Francque, D. van der Graaff, W. J. Kwanten // Journal of Hepatology. - 2016. - Vol. 65. - P. 425-443.

8. Вагrera F. Prothrombotic factors and nonalcoholic fatty liver disease: an additional link to cardiovascular risk? / F. Barrera, J. George // Journal of Hepatology. 2014. - Vol. 59, No. 1. - P. 16-18.

9. Francque S. M. Non-alcoholic fatty liver disease and cardiovascular risk: Pathophysiological mechanisms and implications / S. M. Francque, Denise van der Graaff, W. J. Kwanten // Journal of Hepatology. - 2016. - Vol. 65. P. 425-443.

10. Морозов Ю. А. Нарушения системы гемостаза при патологии печени и их диагностика / Ю. А. Морозов, Р. В. Медников, М. А. Чарная // Геморрагические диатезы, тромбозы, тромбофилии. - 2014. - № 1. C. $162-174$.

11.Уніфікований клінічнийпротокол «Стабільнаішемічна хвороба серця» [Електронний ресурс] / [В. В. Кравченко, М. Ю. Соколов, Т. В. Талаєва та ін.] // Наказ МОЗ України № 152 від 02.03.2016 року. - Режим доступу: http://www.moz.gov.ua/docfiles/dn_20150716_1dod.pdf.

12. Уніфікований клінічний протокол «Неалкогольний стеатогепатит» [Електронний ресурс] / [М. К. Хобзей, 
Огляди літератури, оригінальні дослідження, погляд на проблему

Н. В. Харченко, О. М. Ліщишина та ін.] // Наказ МОЗ України № 826 від 06.11.2014 року. - Режим доступу: httр: // moz.gov.ua/docfiles/dn_20141106_0826_dod_ukp_nsg.pdf.

13. Адаптована клінічна настанова, заснована на доказах «Неалкогольна жирова хвороба печінки» [Електронний ресурс] / [Н. В. Харченко, О. М. Ліщишина, Г. А. Анохіна та ін.]. - 2014. - Режим доступу: http://www. moz.gov.ua/docfiles/dod_akn_dn_20140616_2.pdf.

14. EASL-EASD-EASO Clinical Practice Guidelines for the management of non-alcoholic fatty liver disease // Journal of Hepatology. -2016. - Vol. 64 (6). - P. 1388-1402.

15. Детекторская Л. Н. Лабораторные исследования в клинике / Л. Н. Детекторская, Р. П. Золотницкая. М. : Медицина, 1987. - 368 с.

\title{
REFERENCES
}

1. Kovalenko, V.M. (2016). Problemy zdorovia i medychnoidopomohy ta model pokrashchennia vsuchasnykh umovakh [Health problems and medical care and the model of improvement in modern conditions]. Kyiv [in Ukrainian].

2. World Gastroenterology Organization. Nonalcoholic Fatty Liver Disease and Nonalcoholic Steatohepatitis: World Gastroenterology Organisation Global Guidelines (2012). [cited 2012 Dec 1]. Available from: http://www. worldgastroenterology.org/NAFLD-NASH.html.

3. Zaytseva, O.E. (2016). Nealkogolnyy steatogepatit. Bolshe chem prosto steatoz? [Nonalcoholic steatohepatitis. More than just steatosis?]. Terapiya - Therapy, 7, 111 [in Russian].

4. Stepanov, Yu.M. (2014). Steatoz pecheni i steatogepatit - neizbezhnost smeshannogo geneza [Steatosis of the liver and steatohepatitis - the inevitability of mixed genesis]. Gastroenterologiya-Gastroenterology, 4, 136-142 [in Russian].

5. Fadieienko, H.D., \& Chernyshov, V.A. (2014). Komorbidna patolohiia, shcho vplyvaie na sertsevo-sudynnyi ryzyk u postinfarktnykh khvorykh [Comorbidity affecting cardiovascular risk in postinfarction patients]. Ukrayinskyi terapevtychnyi zhurnal - Ukrainian Therapeutic Journal, 2, 11-20 [in Ukrainian].

6. World Gastroenterology Organization. Obesity: World Gastroenterology Organization Global Guideline (2012). [cited 2012 Dec 1]. Available from: http://www. worldgastroenterology.org/obesity.html.

7. Francque, S.M., van der Graaff, D., \& Kwanten, W.J. (2016). Non-alcoholic fatty liver disease and cardiovascular risk: Pathophysiological mechanisms and implications. Journal of Hepatology, 65, 425-443.

8. Вагrera, F., \& George, J. (2014). Prothrombotic factors and nonalcoholic fatty liver disease: an additional link to cardiovascular risk? Journal of Hepatology, 59, 1, 1618. DOI 10.1002/hep.26588.

9. Sven, M.F., van der Graaff, D., \& Kwanten, W.J. (2016). Non-alcoholic fatty liver disease and cardiovascular

risk: Pathophysiological mechanisms and implications. Journal of Hepatology, 65, 425-443.

10. Morozov, Yu.A., Mednikov, R.V., \& Charnaya, M.A. (2014). Narusheniya sistemy gemostaza pri patologii pecheni i ikh diagnostika [Disturbances of the hemostatic system in the pathology of the liver and their diagnosis]. Gemorragicheskie diatezy, trombozy, trombofilii - Hemorrhagic Diathesis, Thrombosis, Thrombophilia, 1, 162-174 [in Russian].

11. Kravchenko, V.V., Sokolov, M.Yu., \& Talayeva, T.V. (2016). Unifikovanyi klinichnyi protokol «Stabilna ishemichna khvoroba sertsia». Nakaz MOZ Ukrainy № 152 vid 02.03.2016 roku [Unified clinical protocol «Stable coronary heart disease». Order of the Ministry of Health of Ukraine No. 152 from 02.03.2016]. Retrieved from: http://www. moz.gov.ua/docfiles/dn_20150716_1dod.pdf. [in Ukrainian].

12. Khobzey, M.K., Kharchenko, N.V., \& Lishchyshyna, O.M. (2014). Unifikovanyi klinichnyi protokol «Nealkohol'nyi steatohepatyt». Nakaz MOZ Ukrainy \# 826 vid 06.11.2014 roku [Unified clinical protocol «Non-alcoholic steatohepatitis». Order of the Ministry of Health of Ukraine \#826 from 06.11.2014]. Retrieved from: http:// moz.gov.ua/docfiles/dn_20141106_0826_dod_ukp_nsg. pdf. [in Ukrainian].

13. Kharchenko, N.V., Lishchyshyna, O.M., \& Anokhina, H.A. (2014). Adaptovana klinichna nastanova, zasnovana na dokazakh «Nealkoholna zhyrova khvoroba pechinky» [Adapted clinical guidance, based on the evidence «Nonalcoholic fatty liver disease»]. 2014. [Electronic source]. Retrieved from: http://www.moz.gov.ua/docfiles/dod_ akn_dn_20140616_2.pdf. [in Ukrainian].

14. EASL-EASD-EASO Clinical Practice Guidelines for the management of non-alcoholic fatty liver disease (2016). Journal of Hepatology, 64, 6, 1388-1402.

15. Detektorskaya, L.N., \& Zolotnitskaya, R.P. (1987). Laboratornye issledovaniya $v$ klinike [Laboratory research in the clinic]. Moscow: Meditsina [in Russian].

\section{ОПТИМИЗАЦИЯ АНТИТРОМБОЦИТАРНОЙ ТЕРАПИИ У БОЛЬНЫХ СТАБИЛЬНОЙ ИШЕМИЧЕСКОЙ БОЛЕЗНЬЮ СЕРДЦА НА ФОНЕ НЕАЛКОГОЛЬНОЙ ЖИРОВОЙ БОЛЕЗНИ ПЕЧЕНИ В СТАДИИ СТЕАТОГЕПАТИТА}

\author{
ГВуз «Ивано-Франковский национальный медицинский университет»
}

РЕЗЮМЕ. Введение. Показатель сердечно-сосудистой смертности при наличии неалкогольного стеатогепатита (НАСГ) значительно превосходит показатель смертности от заболеваний печени. Установлено, что неалкогольная жировая болезнь печени (НАЖБП) тесно ассоциируется с протромботическим состоянием, что объясняется непосредственным участием печени в гемостазе. 
Огляди літератури, оригінальні дослідження, погляд на проблему

Цель - повышение эффективности и безопасности антитромбоцитарной терапии (АТT) в комплексном лечении больных с постинфарктным кардиосклерозом на фоне НАЖБП в стадии стеатогепатита.

Материал и методы. Обследованы 211 больных со стабильной ишемической болезнью сердца (ИБС) ФК II-III, среди которых выделяли 160 пациентов без НАЖБП (I группа) и 51 пациент с НАЖБП в стадии стеатогепатита (ІІгруппа). Всембольнымпроводилиобщееклиническоеобследование, электрокардиографию, эхокардиографию, коронарографию, ультразвуковое исследование и оценку функционального состояния печени и тромбоцитарного звена гемостаза. Больные получали стандартную терапию в соответствии с действующими клиническими протоколами. Оценку эффективности лечения проводили через 3 и 6 месяцев терапии.

Результаты. Установлено, что эффективность АТТ по показателям агрегационной активности тромбоцитов зависит от наличия НАЖБП, продолжительности лечения, тяжести поражения печени на фоне НАСГ и, соответственно, выбранной схемы дифференцированной АТТ. Определена достаточная эффективность АТТ уже через 3 месяца ее применения у больных со стабильной ИБС без НАЖБП. Однако больные со стабильной ИБС, совмещенной с НАЖБП стадии НАСГ, требуют более длительного проведения коррекции тромбоцитарного гемостаза с обязательным применением дифференцированного подхода к АТТ в соответствии с тяжестью поражения печени.

Выводы. Эффективность воздействия на тромбоцитарное звено гемостаза по показателям агрегационной активности тромбоцитов у больных со стабильной ИБС зависит от наличия НАЖБП и подвергается более тяжелому контролю при НАСГ. У больных со стабильной ИБС, совмещенной с НАЖБП в стадии стеатогепатита, целесообразно контролировать эффективность АТТ каждые 3 месяца ее применения и, при необходимости, проводить ее коррекцию, что предусматривает рассмотрение возможности ее усиления или удвоения в зависимости от состояния печени.

КЛЮЧЕВЫЕ СЛОВА: стабильная ишемическая болезнь сердца; неалкогольная жировая болезнь печени; антитромбоцитарная терапія.

\title{
OPTIMIZATION OF ANTIPLATELET THERAPY IN PATIENTS WITH STABLE CORONARY HEART DISEASE COMBINED WITH NON-ALCOHOLIC FATTY LIVER DISEASE IN STAGE OF STEATOHEPATITIS
}

\author{
Ivano-Frankivsk National Medical University
}

@I. I. Vakalyuk, N. G. Virstyuk

SUMMARY. Introduction. The indicator of cardiovascular mortality in case of non-alcoholic steatohepatitis (NASH) significantly exceeds the mortality rate from liver disease. It was established, that non-alcoholic fatty liver disease (NAFLD) was closely associated with the prothrombotic state, which was explained by the direct involvement of the liver in hemostasis.

Aim - to increase the effectiveness and safety of antiplatelet therapy (APT) in the complex treatment of patients with postinfarction cardiosclerosis combined with NAFLD in the stage of steatohepatitis.

Material and Methods. 211 patients with stable coronary heart disease (CHD) of II-III functional classes were examined. Among them 160 patients without NAFLD (Group I) and 51 patients with NAFLD in the stage of steatohepatitis (Group II) were observed. General clinical examination, electrocardiography, echocardiography, coronary angiography, liver ultrasound, evaluation of the liver functional state and platelet hemostasis were performed to all patients. Patients received a standard therapy in accordance with valid clinical protocols. The evaluation of treatment effectiveness was performed after 3 and 6 months of therapy.

Results. It was established that the efficacy of APT by platelets aggregative activity depends on the presence of NAFLD, the duration of treatment, the severity of liver damage on the background of NASH and, accordingly, the chosen pattern of differentiated APT. The sufficient effectiveness of APT was determined after 3 months of its use in patients with stable CHD without NAFLD. Instead, patients with stable CHD combined with NAFLD in the stage of NASH, required longer duration of platelet hemostasis correction with obligatory application of differentiated approach to APT according to the severity of liver damage.

Conclusions. The effectiveness of the influence on the platelet linkage of hemostasis by the platelet aggregation activity in patients with stable CHD depended on the presence of NAFLD and was more severe controlled in case of NASH. In patients with stable CHD combined with NAFLD in stage of steatohepatitis, it was expedient to control the effectiveness of APT every 3 months of its use and, if necessary, to make its correction, that involved consideration of the possibility of its strengthening or doubling, depending on the liver state.

KEY WORDS: stable coronary heart disease; non-alcoholic fatty liver disease; antiplatelet therapy.

Отримано 12.01.2018 